All three had had many years of homosexual activity and many different sexual partners a year, and therefore their primary infections had probably occurred many years earlier. Our finding of excretion of the virus in these men might indicate that some homosexual men continue to excrete cytomegalovirus in seminal fluid over many years or, alternatively, that there had been recent reinfection, perhaps with a different strain of cytomegalovirus. More probably, however, latent cytomegalovirus re-emerges in men with immunosuppression.

Recently there have been many reports of homosexual men developing illnesses, including Kaposi's sarcoma, that are related to immune suppression. Clinical and epidemiological aspects of these illnesses were recently summarised..$^{12}$ Evidence of abnormal ratios of $\mathrm{T}$ cell helpers to suppressors in apparently healthy homosexual men has also been documented, ${ }^{13}$ and the low ratios reported are similar to those that we found in the older homosexual men who were excreting cytomegalovirus in their seminal fluid. Excretion of cytomegalovirus in the seminal fluid of these more experienced homosexual men and of a homosexual patient with Kaposi's sarcoma is therefore probably the result of immune dysfunction.

This study was supported in part by National Cancer Institute contract Y01CP00502.

\section{References}

${ }^{1}$ Drew WL, Mintz L, Miner RC, Sands M, Ketterer B. Prevalence of cytomegalovirus infection in homosexual men. $\mathcal{f}$ Infect Dis $1981 ; 143$ : 188-92. 1a Melbye M, Biggar RJ, Ebbesen P, Andersen HK, Vestergaard BF. Lifestyle and anti-viral antibody studies among homosexual men in Denmark. Acta Pathol Microbiol Scand (in press).

${ }^{2}$ Jordan MC, Rousseau WE, Noble GR, Stewart JA, Chin TDY. Association of cervical cytomegalovirus with venereal disease. $N$ Engl f Med 1973;288:932-4.

${ }^{3}$ Chretien JH, McGinniss CG, Muller A. Venereal causes of cytomegalovirus mononucleosis. $\mathcal{F} A M A$ 1977;238:1644-5.

4 Lang DJ, Kummer DF. Demonstration of cytomegalovirus in semen. N Engl f Med 1972;287:756-8.

5 Lang DJ, Kummer JF, Hartley DP. Cytomegalovirus in semen: persistence and demonstration in extracellular fluids. $N \mathrm{Engl} \mathrm{f} \mathrm{Med}$ $1974 ; 291: 121-3$.

${ }^{6}$ Lang DJ, Kummer JF. Cytomegalovirus in semen: observations in selected populations. F Infect Dis 1975;132:472-3.

7 Embil JA, Manuel FR, Gainer JB, Coveney L. Cytomegalovirus in the seminal fluid. Can Med Assoc $\mathcal{F} 1982 ; 126: 391-2$.

${ }^{8}$ Andersen HK, Brostrom K, Hansen B, et al. A prospective study of the incidence and significance of congenital cytomegalovirus infection. Acta Paediatr Scand 1979;68:328-36.

${ }^{9}$ Goedert JJ, Neuland CY, Wallen WC, et al. Amyl nitrite may alter $T$ lymphocytes in homosexual men. Lancet $1982 ; \mathrm{i}: 412-5$.

10 Gerstoft J, Malchow-Moller A, Bygbjerg IC, et al. Erhvervet immundefekt hos homosexuelle maend: en nyt sygdomsbillede. (Acquired immunological defect in homosexual men : a new clinical picture.) Ugeskr Laeger $1982 ; 144: 771-6$.

11 Knox GE, Pass RF, Reynolds DW, Stagno S, Alford CA. Comparative prevalence of subclinical cytomegalovirus and herpes simplex infections in the genital and urinary tracts of low-income, urban women. f Infect Dis 1979;140:419-22.

12 CDC Task Force on Kaposi's sarcoma and Opportunistic Infections Epidemiologic aspects of the current outbreak of Kaposi's sarcoma and opportunistic infections. N Engl f Med $1982 ; 306: 248-52$.

${ }^{13}$ Wallace JI, Coral FS, Rimm IJ, et al. T-cell ratios in homosexuals. Lancet $1982 ; \mathrm{i}: 908$.

(Accepted 7 April 1983)

\title{
Schistosomiasis mekongi diagnosed by rectal biopsy
}

\author{
G LORETTE，M R JAAFAR， M F GROJEAN， TH DUONG
}

\begin{abstract}
Schistosoma mekongi, a parasite of the dog which is endemic in small foci along the Mekong river, is rarely seen in Europe. A case of schistosomiasis caused by $\mathbf{S}$ mekongi was recently seen in France, in a native of Laos who had been living in Thailand. He was admitted for treatment of previous diagnosed tuberculoid leprosy but was found to have hepatosplenomegaly, with a high eosinophil count and high bilirubin concentrations. Serological examination suggested schistosomiasis, but there were no parasites in the urine and the rectal mucosa looked normal on endoscopy. Nevertheless, rectal biopsy showed schistosomal proctitis and many ova of $S$ mekongi. Two courses of praziquantel cleared the ova from his rectal mucosa.
\end{abstract}

Although serological examination using $\mathbf{S}$ mansoni

Service de Dermatologie, Centre Hospitalier Universitaire Trousseau, 37044 Tours, France

G LORETTE, MD, médecin adjoint

$M$ R JAAFAR, $M D$, attaché

M F GROJEAN, MD, chef de clinique-assistant

Laboratoire de Parasitologie, Centre Hospitalier Universitaire

Trousseau, 37044 Tours, France

TH DUONG, MD, médecin assistant antigen suggested schistosomiasis, only biopsy of normal looking rectal mucosa allowed the diagnosis to be established.

\section{Introduction}

Schistosoma mekongi is a parasite of the dog. It is endemic in small foci along the Mekong river in Laos and Thailand.'

\section{Case report}

A 21 year old man was admitted for the supervision of his tuberculoid leprosy, diagnosed two years before, and treated with sulphones (dapsone). He was a native of Vientiane (Laos), but had lived in Thailand for two and a half years before his arrival in France. He complained of right hypochondrial pain and had slight conjunctival jaundice. Clinical examination showed hepatosplenomegaly, the spleen extended beyond the costal rim by $3 \mathrm{~cm}$. Blood examination showed hypereosinophilia $\left(8.96 \times 10^{8} / 1\right)$. The total bilirubin concentration was high at $26 \mu \mathrm{mol} / \mathrm{l}(1.5 \mathrm{mg} / 100 \mathrm{ml})$ with a ratio of total to conjugated bilirubin of $7: 1$. Examination of the faeces showed some eggs of Opisthorchis viverrini and some larvae of Anguillula. A serodiagnosis of schistosomiasis was made after an indirect immunofluorescence technique showed a positive response to the antigen $S$ mansoni at a titre of $1 / 40$. There were no parasites in the urine. Rectal endoscopy showed no abnormal changes, but histological examination of two rectal biopsy specimens taken from normal looking rectal mucosa showed lesions of schistosomal proctitis and the presence of 
numerous ova of $S$ mekongi. The patient was treated with praziquantel $75 \mathrm{mg} / \mathrm{kg}$ daily taken in three divided doses three times with intervals of four hours. Four months later he still had some eggs of $S$ mekongi in his rectal mucosa but many of them were black. He was treated again with praziquantel, and three months later there were no parasites in the rectal mucosa.

\section{Discussion}

Schistosomiasis due to $S$ mekongi is rarely diagnosed in Europe. Since 1979 we have investigated the faeces of over 200 refugees from South-east Asia, most of them from Laos and Cambodia, and have found no ova of $S$ mekongi. In the patient described here serological examination with $S$ mansoni antigen yielded slight evidence of schistosomiasis, but only rectal biopsy of normal looking mucosa allowed the diagnosis to be established. Treatment with praziquantel, which is also used to treat $S$ japonicum infections, ${ }^{2}$ was effective after two courses.

\section{References}

1 Voge M, Bruckner D, Bruce JI. Schistosoma mekongi Sp $\mathrm{N}$ from man and animals, compared with four geographic strains of schistosoma japonicum. F Parasitol 1978;64:577-84.

2 Zhejiang Clinical Cooperative Research Group for Praziquantel. Clinical evaluation of praziquantel in treatment of Schistosoma japonica: a report of 181 cases. Chin Med f 1980;93:375-84.

(Accepted 29 March 1983)

\title{
Mycoplasma hominis septicaemia
}

\author{
H FRIIS, A PLESNER, J SCHEIBEL, T JUSTESEN, K LIND
}

\begin{abstract}
Mycoplasma hominis septicaemia occurred in a patient with a malignant lymphoma of lymphoblastic type in leukaemic phase. $M$ hominis was isolated several times from blood cultures with antibody titres against the micro-organism rising to a high level despite severe immunosuppression. $M$ hominis was detected in the blood after subculture of the blood culture bottles despite their macroscopically normal appearance. The patient's pyrexia resolved without treatment with antibiotics effective against $M$ hominis.
\end{abstract}

\section{Introduction}

Mycoplasma hominis is a common inhabitant of the genitourinary tract. ${ }^{12}$ It has been associated with postpartum ${ }^{34}$ and postabortal fever, ${ }^{5}$ and some cases of pyelonephritis have been reported. ${ }^{6}$ Its role as a pathogen in immunosuppressed patients has not, however, been established.

We report a case of severe immunosuppression in a patient in whom $M$ hominis was isolated from several blood samples. The patient developed a high rise in antibody titre despite the severe immunosuppression.

\footnotetext{
Department of Clinical Bacteriology, University of Copenhagen, Institute of Medical Microbiology, Copenhagen, Denmark H FRIIS, MD, registrar

J SCHEIBEL, MD, head physician

T JUSTESEN, MD, head physician
}

Department of Medicine, Finsen Institute, Copenhagen, Denmark A PLESNER, MD, registrar

\author{
Mycoplasma Laboratory, Statens Seruminstitut, Copenhagen, \\ Denmark \\ K LIND, MD, PHD, head physician
}

Correspondence and reprint requests to: Dr H Friis, Department of Clinical Bacteriology, Institute of Medical Microbiology, Juliane Mariesvej 28,2 DK-2100 Copenhagen, Denmark.

\section{Case report}

A 38 year old man with a malignant lymphoma of lymphoblastic type in leukaemic phase was admitted to hospital with a temperature of $38^{\circ} \mathrm{C}$. As shown in the figure, treatment with $\beta$-lactam antibiotics was started on day 2 , firstly with penicillin, then with a combination of methicillin and ampicillin, and later with cefotaxime. Despite treatment his temperature rose to $40^{\circ} \mathrm{C}$. $M$ hominis was isolated from blood cultures on days 4,5 , and 6 . The micro-organism was identified on Hayflick's agar medium ${ }^{7}$ by the disc growth inhibition test ${ }^{8}$ using a rabbit antiserum to $M$ hominis strain PG21. Antineoplastic treatment was started on day 6 with prednisone $75 \mathrm{mg}$ a day, vincristine $1 \mathrm{mg}$ every week, and adriamycin $75 \mathrm{mg}$ on days 7,8 , and 9 .

The day after the start of corticosteroid treatment his temperature returned to normal and antibiotic treatment was stopped on day 10 . On day 11 his temperature rose for a few hours to $39^{\circ} \mathrm{C}$ but no micro-organisms were isolated from the blood or urine. He was treated at home on days 14 and 15 . On day 16 his temperature rose to $40.5^{\circ} \mathrm{C}$ and treatment with ampicillin, methicillin, and netilmicin was started. On day 17 the results of the blood culture were available and clindamycin was added to the treatment regimen in a dose of $600 \mathrm{mg}$ given intravenously four times a day. Over the next two days his temperature remained above $39^{\circ} \mathrm{C}$ and amphothericin $\mathrm{B}$ was given in addition. His temperature gradually returned to normal by day 25. Over this period the granulocyte count was increasing, having been less than $0.5 \times 10^{\%} / 1\left(500 / \mathrm{mm}^{3}\right)$ since day 10 and less than $0.1 \times 10^{9} / 1\left(100 / \mathrm{mm}^{3}\right)$ from day 14 to day 21 .

Blood cultures carried out on days $11,16,17,18$, and 19 failed to yield $M$ hominis or other pathogens. Throat swabs and midstream urine samples did not grow $M$ hominis on culture. The bladder was not catheterised. Antibody titres against $M$ hominis, as determined by an indirect haemagglutination test ${ }^{9}$ on days 5,13 , and 29 , were 80,1280 , and 640 respectively.

The blood samples were cultured under aerobic and anaerobic conditions for seven days in Hemobact ${ }^{\circledR}$ (Orion Diagnostica, Finland; see table). Routinely the bottles were inspected daily and subcultures made on the first and fifth days. On inspection there were no signs of growth, but routine subcultures from both the aerobic and anaerobic bottles on the blood agar plates on day 5 yielded growth after two days of anaerobic incubation. The colonies were pinpoint and translucent and Gram stained smears did not show any micro-organisms. The final diagnosis was made by the mycoplasma laboratory at the Statens Seruminstitut.

Antibiotic susceptibility testing was carried out by the single disc diffusion technique using discs from Bio Disc ${ }^{\circledR}$ (Solna, Sweden). ${ }^{10}$ Susceptibility tests showed sensitivity of $M$ hominis to gentamicin, netilmicin, fusidic acid, chloramphenicol, and clindamycin and resistance to $\beta$-lactam antibiotics, streptomycin, vancomycin, polymyxin, tetracycline, and erythromycin. 